\title{
SOBRE LA SANCIÓN POR LA OMISIÓN DE LA AUTORIZACIÓN ESTABLECIDA EN EL NÚMERO 4 DEL ARTÍCULO 57 DE LA LEY SOBRE SOCIEDADES ANÓNIMAS
}

\section{Andrés Cuneo Macchiavello}

Profesor de Derecho Civil

Universidad Diego Portales

1. Este informe tiene por finalidad intentar resolver la cuestión que se ha planteado en torno a las formalidades que serían necesarias para que una sociedad anónima pueda enajenar bienes que representen una proporción equivalente o superior al $50 \%$ de sus activos, en los términos indicados en la disposición a que alude el título de este trabajo.

2. En efecto, la disposición aludida indica que constituye materia de una junta extraordinaria:

"La enajenación del activo de la sociedad en los términos que señala el $\mathrm{N}^{\circ} 9$ del artículo 67, o el $50 \%$ o más del pasivo".

Por su parte, el artículo 67, que se refiere a los quórum que se deben reunir en las juntas extraordinarias determina, en su número 9 que, en estas sociedades, deberá contarse con el voto conforme de las dos terceras partes de los acciones emitidas con derecho a voto para: "La enajenación de un $50 \%$ o más de su activo, sea que incluya o no su pasivo"...

3. Las disposiciones en comento no consignan una sanción expresa para el caso de incumplimiento de este requisito, lo que ha planteado dudas a quienes deben aplicar la disposición y soportar los efectos del eventual incumplimiento del mismo.

4. La cuestión presenta, adicionalmente, una gran dificultad práctica a la hora de resguardar los derechos de terceros que contratan con la sociedad. En efecto, éstos, por su natural condición de ajenos a la administración de la misma, no tienen la información ni el control suficientes para determinar con seguridad si se dan o no los supuestos fácticos que hacen necesaria la aprobación de la junta en los casos que se estudian. Por otra parte, también existen dificultades en lo que se refiere a la eventual sanción, en vista del silencio legal. Hay discusión, ya que existen quienes piensan que la omisión trae aparejada la nulidad absoluta del acto de enajenación, otros que estiman que se produce su nulidad relativa y algunos, finalmente, que platean su inoponibilidad.

5 . El texto vigente, citado en el párrafo segundo de este informe, se incorporó a la Ley sobre Sociedades Anónimas por mandato de la ley $\mathrm{N}^{\mathrm{O}}$ 19.705, de 2000. Hasta donde llega el conocimiento de este abogado, no se ha producido todavía jurisprudencia 
administrativa sobre la materia y, obviamente, tampoco jurisprudencia judicial. En razón de lo anterior, este informe intenta proponer sólo una solución dogmática, elaborada a partir de una interpretación fundada en los métodos lógico y sistemático que consagran los artículos 19 y 22 del Código Civil. Se hace también una referencia a la historia de la ley

6. En opinión de este letrado, conviene iniciar este análisis con una consideración acerca de la estructura jurídica de la sociedad anónima, de modo de contrastar con ella la hipótesis que se planteará más adelante.

7. La Ley sobre Sociedades Anónimas -en lo sucesivo, la Ley- contempla dos órganos principales para la formación de la voluntad de estas

228 entidades: el directorio y la junta de accionistas. Simplificando, se puede decir que al primero corresponden principalmente las gestiones relacionadas con la administración de la sociedad y, a la segunda, las decisiones político institucionales de la misma.

8. Se entiende, para los efectos de este informe, por cuestiones político-institucionales, aquéllas que se relacionan con la elección de las personas que gestionan a la sociedad y con la configuración de la personalidad jurídica de la misma, esto es, con su estatuto. Se entiende por administración, la gestión conducente a realizar el giro social

9. El artículo 31 de la Ley sólo establece:

"La administración de la sociedad anónima la ejerce un directorio elegido por la junta de accionistas".

En cambio, el artículo 55 y siguientes de la misma Ley enuncian un conjunto complejo de materias, algunas de las cuales sólo pueden tratarse en juntas extraordinarias citadas para este efecto que, en ciertos casos, incluso requieren de mayorías especiales.

10. Con todo, como se indicó, la atribución del carácter de órgano político-institucional a la junta de accionistas no pasa de ser una simplificación. En efecto, si se examinan sus atribuciones, se puede concluir que algunas de ellas tienen una marcada naturaleza político-institucional, mientras que otras se relacionan primordialmente con la administración.

11. Pertenecen, sin duda, a la primera categoría, atribuciones tales como la elección o revocación de los miembros titulares y suplentes del directorio $\left(\mathrm{N}^{\mathrm{O}} 3\right.$ del artículo 56 de la Ley); también la facultad de acordar la disolución de la sociedad o su transformación, fusión o división y, en general, la reforma de sus estatutos $\left(\mathrm{N}^{\mathrm{os}} 1\right.$ y 2 del artículo 57 de la Ley). Corresponden, en cambio, más bien a la administración, facultades tales como la aprobación o rechazo de la memoria y el balance y la distribución de la utilidad ( $\mathrm{N}^{\mathrm{os}} 1$ y $2 \mathrm{del}$ artículo 56).

12. El tema que nos ocupa hace relevante la distinción que se ha hecho en los párrafos anteriores. En efecto, en principio, a los terceros le interesan, porque les afectan, aque- 
llas cuestiones que se vinculan a lo institucional de la sociedad, porque ellas determinan su actuación dentro del giro, la capacidad y la calidad jurídica de los personeros con que se manifiesta su voluntad para celebrar actos jurídicamente vinculantes.

13. Por ejemplo, el objetivo de la sociedad, que se debe expresar en su estatuto (artículo $4^{\circ} \mathrm{N}^{\mathrm{o}} 3$ de la Ley) puede llegar a determinar que un contrato celebrado con ella esté considerado dentro de su giro o que resulta exorbitado. De una u otra situación dependerá, no la validez del acto mismo, sino su oponibilidad a la sociedad. El acto exorbitado es un acto del administrador o representante legal que no da acción respecto de la persona jurídica que administra. El acto ejecutado dentro del giro, sí. Todo esto no es sino una consecuencia del carácter ficticio que tiene la persona jurídica, en nuestro sistema de Derecho, como se desprende de la definición del artículo $545 \mathrm{del}$ Código Civil.

14. Lo mismo se puede decir acerca de la forma de tomar acuerdos jurídicamente vinculantes. Por ejemplo, para que la sociedad se obligue para con terceros es necesaria la actuación de su directorio. Éste debe hacerlo funcionado en sala legalmente constituida (artículo 39 inciso primero de la Ley). Por ello, a los terceros que contratan con la sociedad no les es indiferente si hubo o no acuerdo del directorio y si éste funcionó del modo que establece la Ley.

15. Por el contrario, aquellos actos de administración que sólo producen efectos internos para la sociedad, como la decisión de la junta de distribuir o no un dividendo o la aprobación de la memoria y balance, son cuestiones que no afectan a terceros, ya que no implican la creación de vínculos jurídicos que, eventualmente, puedan ser ineficaces o inoponibles a la sociedad.

16. Es necesario dejar en claro que la circunstancia que un acto carezca de relevancia, con respecto de terceros, no significa que carezca de consecuencias jurídicas. Así, por ejemplo, la fijación de la remuneración de los directores es algo que atañe a la junta de accionistas (artículo 33 de la Ley), que produce efectos jurídicos, pero que no afecta a los terceros, incluso, en el caso que los directores procedieran, por ejemplo, con infracción de los estatutos sociales o de la propia ley.

17. En esta misma línea de análisis es importante dejar en claro que una infracción a la ley o a los estatutos sociales puede producir efectos muy diversos; por un lado, en lo que toca a la sociedad y sus accionistas o entre aquélla y éstos y los directores $y$, por otro lado, con respecto a terceros que contratan con la sociedad. Lo afirmado se perfila con claridad, por ejemplo, en las disposiciones de la Ley que se refieren a las operaciones relacionadas que regula su artículo 44 .

18. La disposición referida establece una serie de mecanismos y cautelas tendientes a evitar los perjuicios que una sociedad anónima pueda experimentar por la celebración de actos o 
contratos en los cuales uno o más de sus directores tengan interés por sí o como representantes de otra persona. 19. El inciso 15 del artículo referido, sanciona las infracciones por incumplimiento de dichos mecanismos y cautelas. Dispone:

"La infracción de este artículo no afectará la validez de la operación, pero además de las sanciones administrativas en su caso y penales que correspondan, otorgará a la sociedad, a los accionistas o a los terceros interesados, el derecho de exigir indemnización por los perjuicios ocasionados y pedir el reembolso a la sociedad por el director interesado, de una suma equivalente de los beneficios que a él, a sus parientes o a sus representados les hubiera reportando dichas negociaciones".

20. La disposición transcrita efectúa una clara distinción con respecto a los efectos de un mismo acto que infringe la ley o los estatutos sociales. El acto no es nulo. El texto legal señala que la infracción no afecta la validez de la operación y que sólo genera el deber de indemnizar. Dado que el acto no es nulo, el tercero -que, incluso, puede ser el propio director interesado- queda a salvo con respecto a las consecuencias del acto jurídico, aunque éste contravenga las normas legales que regulan los conflictos de interés de que trata el artículo 44. En otras palabras, el acto que infringe una disposición legal o estatutaria de una sociedad anónima, puede no tener los mismos efectos en lo que respecta a sus propios socios o personas que constituyen los órganos, por una parte, y los terceros a ella, por otra. Los terceros quedan a salvo y los otros son sancionados con los perjuicios o con la obligación de restituir lo indebidamente ganado.

21. El inciso 15 del artículo 44 de la Ley constituye, en el fondo, una particularísima aplicación del mismo principio consagrado en el artículo 10 del Código Civil:
"Los actos que prohíbe la ley son nulos y de ningún va- lor; salvo en cuanto designe expresamente otro efecto que el de nulidad para el caso de contravención".

22. Establecidos los anteriores presupuestos, se pasa a analizar la disposición que origina este informe, de modo de resolver la sanción aplicable para el caso del acto de enajenación que no cumpla con el requisito de haber sido aprobada por los dos tercios de las acciones emitidas. Para ello, resulta necesario reflexionar sobre la naturaleza de tal acto y su posible consecuencia respecto de terceros.

23. Los actos que deben contar con la autorización referida, como hemos visto, son aquéllos que impliquen...
1) "La enajenación de un $50 \%$
o más de su activo, sea que incluya o no su pasivo"... $\mathrm{y}$ 
2) "la formulación o modificación de cualquier plan de negocios que contemple la enajenación de los activos por un monto que superior al porcentaje antes dicho".

24. Aplicando la distinción que se ha hecho respecto de las decisiones que puede tomar una sociedad anónima, cabe preguntarse si acaso esta disposición corresponde a aquéllas que pueden surtir sus efectos respecto de terceros por la vía de la nulidad o de la inoponibilidad o, bien, si ella es una norma destinada a tener efectos internos y, por consiguiente, su omisión implica una sanción que no consiste en un perjuicio o pérdida de ventaja para el tercero.

25. En opinión de este abogado, resulta necesario descartar, desde ya, la posibilidad de una nulidad absoluta del acto ejecutado sin la autorización de la junta en razón de que este tipo de nulidad sólo puede estar establecido por texto legal expreso y debe provenir de una causa u objeto ilícitos o por la omisión de algún requisito o formalidad que las leyes prescriben para el valor de ciertos actos o contratos en consideración a la naturaleza de ellos y no a la calidad o estado de las personas que los ejecutan o celebran (artículo 1682 inciso primero del Código Civil).

26. El acto de enajenación que se estudia, en la situación bajo análisis, no tiene requisitos propios, sino los requisitos generales correspondientes al acto o contrato que se trata, así, deberá constar por escritura pública, si se trata, por ejemplo, de la compraventa que recae sobre un inmueble. Con todo, la autorización del $\mathrm{N}^{\mathrm{o}}$ 4 del artículo 57 de la Ley puede estimarse un prerrequisito para la celebración del contrato referido en el ejemplo, pero jamás un requisito del mismo, exigido en consideración a su naturaleza de compraventa de un bien raíz social.

27. La nulidad relativa tampoco parece ser la sanción pertinente porque ella corresponde a dos situaciones genéricas: a la omisión de un requisito exigido en atención a la calidad o estado de la parte que celebra el acto o contrato o la existencia de un "vicio" en dicho acto o contrato (artículo 1682 del Código Civil).

28. En nuestro caso, no hay un problema de capacidad, ya que las personas jurídicas son siempre plenamente capaces. Desde el momento que la persona jurídica existe para el Derecho, posee capacidad de goce y de ejercicio. No procede que ella actúe representada o autorizada para suplir su incapacidad. Si los representantes de la sociedad actúan fuera del giro u objeto social o de su mandato, como hemos visto, no realizan un acto nulo, sino exorbitado, inoponible a la sociedad misma, pero válido respecto de su representante y del tercero que con él actúa.

29. En lo que toca a la sanción genérica de nulidad relativa que contempla el inciso final del artículo 1682, esto es:

"Cualquier otra especie de vicio produce nulidad relati- 
va y da derecho a la rescisión del acto o contrato",

ella se refiere al vicios propios del acto y no a defectos en razón a la calidad o estado de las partes, como son el error, la fuerza y el dolo. La omisión del requisito en comentario no incide, no se produce en el acto mismo celebrado con el tercero sino en la formación de la voluntad de la persona jurídica, por lo que no se asemeja en nada ni se puede asimilar a dicha sanción genérica.

30. La tercera alternativa de sanción es la inoponibilidad, por considerar que, por haberse contratado de este modo, el acto celebrado, sin ser nulo, no obliga a la sociedad ni da acción en contra de ella.

232
31. En este punto resulta conveniente volver a la distinción que se hacía en párrafos anteriores, relacionada con la naturaleza del acuerdo de la junta, exigido por el artículo 57 $\mathrm{N}^{\mathrm{O}} 4$ de la Ley, esto es, si se trata de una actuación político-institucional o de mera gestión patrimonial.

32. La autorización en cuestión no constituye, desde ningún punto de vista un acuerdo de naturaleza político-institucional, puesto que no incide ni en el estatuto de la sociedad ni en la elección de sus personeros y administradores.

33. Ciertamente la finalidad de la disposición consiste en evitar que los administradores de la sociedad, por medio de simples acuerdos de directorio, la priven de una parte significativa de su patrimonio -que la disposición fija en 50\% o más de sus activos- sea que ello tenga lugar en un solo acto o, bien, mediante actos sucesivos durante un período de doce meses consecutivos, relativos a un bien social (artículo $67 \mathrm{~N}^{\circ} 9$ de la Ley). Para proceder a tan importante enajenación, entonces, la Ley exige acuerdo de junta, tomado con el voto conforme de las dos terceras partes de las acciones emitidas con derecho a voto, según el encabezado del inciso segundo del referido artículo 67.

34. Como se puede apreciar, el requisito previo al acto de enajenación que, en el caso, es una autorización de la junta en los términos señalados, tiene por finalidad cautelar la conservación del patrimonio social.

35. En principio, la conservación del patrimonio puede interesar a terceros acreedores o a los propios accionistas que no concurren al acuerdo, es decir, a los minoritarios.

36. Los terceros, en verdad, no quedan protegidos por medio de este mecanismo de acuerdo de junta y quórum especial, ya que si se tratara de evitar que la sociedad pudiera disponer de bienes en perjuicio suyo, tal mecanismo resultaría ineficaz, pues siempre quedarían entregados a la sola voluntad del deudor, cualesquiera que sean los requisitos que se deba cumplir de acuerdo con las normas estatutarias. Las acciones para proteger a los terceros frente a las enajenaciones perjudiciales del deudor son otras: entre ellas, la acción pauliana civil o las paulianas concursales.

37. Por descarte, pues, el examen dogmático de la disposición conduce 
a pensar que el mecanismo de la autorización del $\mathrm{N}^{\mathrm{O}} 7$ del artículo 54 de la Ley no está destinado sino a producir efectos internos respecto de la sociedad y que, en razón de su estructuración jurídica -esto es, que la junta de accionistas sea el órgano competente y que la decisión deba ser tomada con un alto quórumtiene por objetivo proteger a los minoritarios, impidiendo que el o los controladores puedan disponer con libertad de la mayor parte de su patrimonio, en perjuicio suyo. De este modo, una decisión que afecta tan radicalmente el patrimonio social no puede sino tomarse con el concurso de la mayoría calificada que establece el tantas veces referido artículo 67 de la Ley.

38. Esta interpretación se ve reforzada por dos consideraciones, una adicional de carácter dogmático y otra que considera la historia de la Ley.

39. La primera de ellas se encuentra en el propio texto del número 9 del artículo 67 de la Ley. En su parte pertinente, este expresa:

"Requerirán del voto conforme... "9) La enajenación de un 50\% o más de su activo, sea que incluya o no su pasivo; como así mismo, la formulación o modificación de cualquier plan de negocios que contemple la enajenación de activos por un monto que supere el porcentaje antes dicho".
40.Ya se ha abundado sobre la primera parte de la disposición. La segunda se refiere a un acuerdo que, al momento inicial, al menos, sólo produce efectos internos, como es la aprobación o modificación de un plan de negocios. Este solo acuerdo, independientemente de si llega o no a producir efectos de enajenación $-y$, por tanto, respecto de terceros- debe ser tomado por la mayoría calificada que exige la disposición en comento. Se sigue de lo dicho que ésta es una regla de gestión cuya única finalidad no puede sino exigir una voluntad compartida para las decisiones que inciden sobre la materia que se analiza.

41. En lo que toca al argumento de la finalidad de la Ley, los antecedentes legislativos no pueden ser más contundentes. En efecto, en el Mensaje del Ejecutivo con el que se inicia la tramitación del proyecto de ley (Mensaje No 2289-05), se expresa, en el párrafo correspondiente a los objetivos, que no obstante ampliarse las facultades de administración,

..."como contrapeso a favor de los accionistas minoritarios, se otorgan mayores resguardos de protección a sus intereses como inversionistas, elevando los quórum de acuerdo para transformación, fusión, creación de preferencias y otros casos que pueden establecer los estatutos. Asimismo, se aumentan doblemente los requisitos para los acuerdos relativos a la enajenación y 
constitución de garantías cuando se comprometan activos sociales, exigiendo ahora un quórum más alto y el monto comprometido sea el equivalente al 50\% o más de los activos".

Esta idea es recogida expresamente en el informe de la Comisión de Hacienda de la Cámara de Diputados y se incorpora en el texto de la Ley mediante la modificación introducida en ella por el artículo $2^{\circ}$ de la ley $\mathrm{N}^{\circ} 19.705$ publicada en el Diario Oficial de fecha 20 de diciembre de 2000.

42. Como es obvio, las normas protectoras de los intereses sociales o de los accionistas minoritarios 234 regulan las relaciones entre los administradores y los accionistas y no las de la sociedad con terceros. La regla básica, en este punto es la contendida en el artículo 41 de la Ley:

"Los directores deberán emplear en el ejercicio de sus funciones el cuidado y diligencia que los hombres emplean ordinariamente en sus propios negocios y responderán solidariamente de los perjuicios causados a la sociedad y a los accionistas por sus actuaciones dolosas o culpables".

\section{Por su parte el artículo $42 \mathrm{~N}^{\mathrm{o}}$} 7 prohíbe a los directores:

"En general, practicar actos ilegales o contrarios a los esta- tutos o al interés social... Los beneficios percibidos por los infractores a lo dispuesto en los últimos tres números de este artículo pertenecerán a la sociedad, la que además deberá ser indemnizada por cualquier otro perjuicio".

44. Los párrafos anteriores indican cuál es la sanción por la omisión de la autorización que origina este informe: la enajenación o la aprobación de un plan de negocios de la magnitud indicada por la disposición legal hace responsables, a los directores que incurrieron en ella, de todo perjuicio y, a la sociedad, dueña de la utilidad que pudieron haber obtenido por medio de tal maniobra. Esta sanción no alcanza, por definición, a los terceros que pueden haber contratado con la sociedad, cuando sus personeros han infringido la correspondiente prohibición.

45. Por lo demás, el sentido común conduce a la misma solución. ¿Cómo puede tener seguridad un tercero, acerca de la circunstancia de hallarse o no en el ámbito de aplicación de la norma? El tercero debería exigir siempre el acuerdo de junta porque no tiene nunca seguridad absoluta de si el activo que está adquiriendo representa o no el $50 \%$ o más de los activos sociales. Éste no puede ser el efecto querido por el legislador, pues traba severamente el gobierno corporativo y la circulación de los bienes. Por otro lado, la determinación de la importancia patrimonial de un bien 
dentro de los activos sociales es una de la autorización prevista en el núinformación que proviene siempre mero 4 del artículo 57 de la Ley no de la sociedad, a través de sus estados financieros. ¿Puede la seguridad de un negocio quedar entregada a esta sola información que proporciona una de las partes? La respuesta es que no puede ser así.

46. En síntesis, argumentos de texto legal coordinados entre sí y en función de su contexto, la historia de la ley y el propio sentido común, indican que la sanción por la omisión puede consistir ni en la nulidad ni en la inoponibilidad del acto que la contraviene, pues ello implicaría una sanción también para el tercero. La sanción debe buscarse dentro de la red de derechos subjetivos que existen entre la sociedad, sus accionistas y sus directores y ella no es otra que la indemnización de perjuicios y la restitución eventual de lo indebidamente ganado por parte de los infractores. 